\title{
Mercury Extraction in Presence of Cobalt Using Hollow Fiber Supported Ionic Liquid Membrane
}

Mahmudul Hasan Khan Neon and Jayakumar Natesan Subramanian Nayagar

Chemical Engineering Department, University of Malaya, Malaysia

*Corresponding author: Mahmudul Hasan Khan Neon, Banasree, Rampura, Dhaka-1219, Bangladesh, Tel: +8801715029061; E-mail: neon4khan@gmail.com.

Received date: May 8, 2017; Accepted date: June 5, 2017; Published date: June 8, 2017

Copyright: $@ 2017$ Neon MHK. This is an open-access article distributed under the terms of the Creative Commons Attribution License, which permits unrestricted use, distribution, and reproduction in any medium, provided the original author and source are credited

\begin{abstract}
In the current study, the removal efficiency of mercury in presence of cobalt was examined through the hollow fiber supported liquid membrane unit. The micro-porous polypropylene supported material was impregnated by Aliquat 336 (Tri-octyl-methyl-ammonium chloride) where toluene was used as a diluting agent. The experiments were carried under $25^{\circ} \mathrm{C}$ temperature and 1 atmospheric pressure. The feed solution was maintained at $\mathrm{pH}$ level lower than equal to 1.5 and the stripping agent i.e. thiourea solution was maintained at $\mathrm{pH}$ level greater than equal to 3.0. The mercury concentration ( $\mathrm{ppb}$ ) was analyzed by using HydrEA HS6 (I) analyzer. The data obtained in the present study showed that the increase in the concentration of cobalt till the same concentration of mercury in feed solution enhances the percentage removal of mercury. The most favorable value for the ionic liquid concentration within the range of $0.1 \mathrm{M}-0.2 \mathrm{M}$ was found to be $0.1 \mathrm{M}$ for the removal of mercury. The optimal value of the stripping agent concentration within the range of $0.025 \mathrm{M}-0.075 \mathrm{M}$ was found to be $0.05 \mathrm{M}$ whereas the optimal value for the volumetric flow-rates of stripping agent and feed inlet within the range of $50 \mathrm{ml} / \mathrm{min}-200 \mathrm{ml} / \mathrm{min}$ laid between $100 \mathrm{ml} / \mathrm{min}-150 \mathrm{ml} / \mathrm{min}$ for the best possible percentage removal of mercury. For the system operating close to the optimum and encouraging conditions, it was possible to remove mercury to almost $60 \%$ of the feed inlet value.
\end{abstract}

Keywords Mercury; Cobalt; Ionic liquid; Hollow fiber supported liquid membrane; Thiourea; Toluene; HydrEA HS6(I)

\section{Introduction}

Mercury is one of the heavy metals which are considered being toxic, persistent and non-biodegradable in the environment $[1,2]$. The persistence phenomenon is considered as a sign of worry when it is subjected to human body. In recent studies it was found that even a small dose of mercury can have a severe negative impact on the human nervous system, immune system and also can damage other major parts of human body like lungs and kidney $[3,4]$. In nature, mercury is present in three different forms - elemental, inorganic and organic along with other metals like cobalt, arsenic and copper. Most of the time, they exist naturally and possess some natural bonding along with each other. The property of mercury toxicity is based on the redox and the transport route it follows until it reaches the human body. The most toxic state of mercury is the mercury two plus ion which has an extra tendency to bind itself with proteins specifically in human body and subsequently causes lethal impact.

The typical source of mercury is considered to be the industrial discharge, mining and combustion activities [5]. All these sources generate mercury waste in many different forms and states. In contrast to the Malaysian environment, the maximum discharge of mercury is considered to be around 5 parts per billion (ppb) stated by the Malaysia Environmental Quality (Sewage \& Industrial Effluents) [6] In recent years, the adverse effect of mercury and other heavy metals has become an alarming indication for the Malaysian environment. The reason is development of industrialization and thus requires some serious extra thoughts along with awareness.

Membr Sci Technol, an open access journal

ISSN:2155-9589
The mercury is found in trace amounts and therefore requires a very efficient removal technique. Currently, there are many types of treatment technique recommended for the removal of mercury like filtration, adsorption, ion exchange, solvent extraction and membrane separation. The draw-back for most of these techniques is that their removal effectiveness decreases along with the concentration level of mercury. In addition, most of these techniques got high controlling and maintenance costs with some vital process limitations. At this moment of time, the mercury waste producing industry uses adsorption mechanism and in some cases they also prefer membrane techniques to remove mercury. The typical adsorption method following equipment is a packed bed column. The packed bed column is used to absorb mercury into organic solutions and simultaneously, the stripping agent is regenerated by heating or pressure swing. The technology is very energy-consuming and not easy to control because of some common problems like frequent foaming and flooding during the process operation.

The most recent research showed that the liquid impregnated membrane (LIM) separation techniques are admirable for the purpose of efficient mercury removal and especially from its corresponding aqueous state. LIM uses the extraction separation technique along with the diffusion technique. In general, LIM system contains two different liquid phases which are separated by a semi-permeable micro-porous film and filled with the carrier. The phenomenon of the mass transfer happen as the targeted ions diffuse through the filled membrane pores from the feed phase to the stripping solution. Liquid membrane has a number of advantages over the other conventional methods for example operating flexibility, high surface area to volume ratio, and compact dimension.

The existing types of the liquid membrane are bulk-liquid membranes (BLM), emulsion-liquid membranes (ELM) and 
supported-liquid membranes (SLM). The bulk liquid membranes are simple to set up and functional cost is very low but unfortunately the surface area to volume ratio value is very small. The emulsion-liquid membrane provides an acceptable value for the surface area to volume ratio but in terms of stability there is a major concern. On the other hand, the newest technique of supported liquid membrane has many advantages like costing, control and maintenance. The initial costs for the set-up along with the operating costs are very low. The arrangements are very simple to operate even under a continuous-flow condition [7]. Recent research showed that the supported liquid membrane technique has a great potential for the removal of the heavy metal ions from the industrial runoff streams [8-10].

The performance of the membrane system is also dependent on the types of membrane module or contractor. The micro porous hollow fiber membrane contactors (HFMC) are expected to have the promising nature to overcome the drawbacks of orthodox membrane equipment and guide the metal removal technology to a whole new level. The efficiency of a membrane system is dominated by the controlling factors like higher mass transfer coefficient. The mass transfer coefficient is a function of the mass transfer area available. HFMC offers a huge amount of effective mass transfer area, so HFMC is somewhere more efficient than the other membrane contractor technologies. HFMC has also shown the sign of reducing the size of the absorber and stripper units by 63\%-65\%. These advantages have helped HFMC to receive huge attention especially for industrial applications.

Although, there is an exceptional separation capability and a wide scope for application, hollow fiber supported liquid membrane (HFSLM) sometimes exhibits stability problem. The problem is due to the liquid properties loaded in the pores. The most common types of the supported liquid are the organic carriers. The organic carriers are not stable in the membrane system because of their high volatile property during the operation. The major problem with organic carrier is the rupture of the membrane materials or structures because of the liquid loss due to vaporization. Additional attention is given on HFSLM for the improvement of it by stopping the loss of liquid materials to maintain the structural attire. In current situation, many of the researchers sense that the ionic liquid can be considered as the most suitable green replacement for the organic carriers. The ionic liquid's (IL) exclusive properties such as insignificant vapor pressure, immiscibility with organic solvents and water makes it the perfect candidate as a supported liquid [11-13].

The major focus of this particular study is to indicate the performance of the separation unit. All the criteria stated above are taken into consideration and a separation unit which consists of a hollow fiber supported liquid membrane impregnated by ionic liquid (Aliquat 336) as supported liquid is selected as the base equipment of this research. The objectives set for the research are:-

- To determine the mercury removal efficiency of the hollow-fiber supported ionic liquid membrane separation system.

- To examine the effect of cobalt on mercury separation process as a contaminant.

- To obtain the optimum and appropriate values for the variable parameters to achieve maximum performance from the separation system.

It is believed that the findings of the proposed research will show and justify how the efficiency of the membrane system in terms of mercury removal can be improved by using hollow fiber supported ionic liquid membrane with respect to variable parameters.

\section{Methodologies}

\section{Materials}

Ionic liquids: The most suitable ionic liquid found for this particular research is Aliquat 336 (Sigma Aldrich, supplied by R\&M chemicals) which is considered to react with the targeted mercury ions to produce mercury complex molecules which diffuses across the membrane to the stripping interface and chemically reacts with the selected stripping agent where the mercury ion is being stripped off and the extractant or the carrier is being regenerated $[14,15]$.

Toluene: Toluene (Merck, Malaysia) has been selected as a diluent or a solvent of the ionic liquid. The selection is done based on the volatility of the diluent. The toluene is expected to carry the viscous ionic liquid to the hollow fiber membrane module and vaporize itself without any kind of impact on the system, so the ionic liquid is the only liquid that is anticipated to remain in the pores of the membrane.

Mercury (II) Chloride and Cobalt (II) Chloride: Both mercury (II) chloride (Sigma Aldrich, supplied by R\&M chemicals) and cobalt (II) chloride (Sigma Aldrich, supplied by R\&M chemicals) salts are in hydrated form and is expected to have around 99\% purity. The potential standard of quality for both the salts is of $R \& D$ sector quality.

Thiourea: The choice of the stripping agent is done between the common alkaline solutions and thiourea. The thiourea (Sigma Aldrich, supplied by R\&M chemicals) is selected as the stripping agent and the sole reason behind this is that it doesn't form precipitation that easily compare to the other stripping agents like $\mathrm{NaOH}$ and $\mathrm{KOH}$.

Others: Hydrochloric acid (Sigma Aldrich, supplied by R\&M chemicals) with a purity of $99 \%$ is used in the feed and stripping solution to maintain the $\mathrm{pH}$ level. A very small amount of nitric acid and mercury (II) chloride of commercial standard are also used for the analysis of the mercury by HydrEA.

\section{Equipment}

\begin{tabular}{|l|l|}
\hline \multicolumn{1}{|c|}{ Properties } & \multicolumn{1}{c|}{ Quality/Quantity } \\
\hline Materials of Construction & Poly-propylene \\
\hline Effective membrane surface area & $1.5 \mathrm{~m}^{2}$ (approximately) \\
\hline Effective membrane length & $0.15 \mathrm{~m}$ \\
\hline Internal diameter (Hollow fiber) & $220 \times 10^{-6} \mathrm{~m}$ \\
\hline External diameter (Hollow fiber) & $300 \times 10^{-6} \mathrm{~m}$ \\
\hline Total number of the fibers & $10800($ approximately) \\
\hline Porosity of the membrane & 0.5 \\
\hline Pore size of the membrane & $0.03 \times 10^{-6} \mathrm{~m}$ \\
\hline Tortuosity of the membrane & 2.5 (approximately) \\
\hline
\end{tabular}

Table 1: Membrane characteristics.

Hollow fiber supported liquid membrane (Liqui-Cel ${ }^{\bullet}$ Membrane Contactor): The micro porous hollow fiber membrane is predicted to 
Page 3 of 7

have the promising nature to guide mercury removal technology to a different level. The efficiency of hollow fiber membrane is very high compare to the other sort of membrane contractors. Hollow fiber membrane has compact size and hydrophobic property (as it is made of polypropylene) which makes it a perfect choice for this research. Some of the properties of the proposed HFSLM are given below in Table 1.

Set-up of the hollow fiber supported liquid membrane: The set-up consists of two gear pumps supported with the flow-rate controllers and the pressure gauges. It also has four supported vessel containers required to up-hold the solutions and is constructed of glass (for the purpose of the impurity) Figure 1.

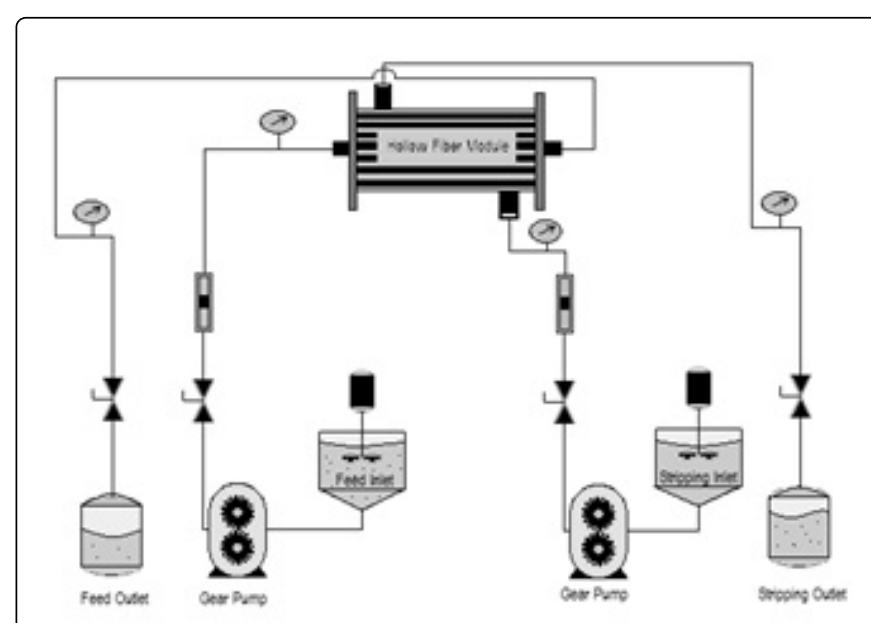

Figure 1: Set-up of the hollow fiber supported liquid membrane.

HydrEA HS6(I): HydrEA HS6(I) has the capability to measure the mercury concentration close to $1 \mathrm{ppb}$ and also has the extrapolation mechanism technique to give reading which is above or below the initial boundary limits. The HydrEA has all the required function that is needed in this particular research, so has been selected.

\section{Experimental Procedures}

The feed and stripping solutions preparation: A theoretical calculated amount of mercury (II) chloride and the cobalt (II) chloride was added to the distilled water and stirred for almost 20 minutes. Hydrochloric acid of a certain amount was added to the salt solution and the $\mathrm{pH}$ level was maintained below 1.5. The final solution was again stirred for another 15 minutes. For the case of stripping agent, a theoretical calculated amount of thiourea crystals were added to the distilled water and stirred until the solution became homogeneous. The mixing process was followed by the addition of the hydrochloric acid, where a $\mathrm{pH}$ level above 3.0 was maintained. Both the solutions were stored in the controlled area after the preparation till the experiments were carried out.

The extractant preparation and impregnation: A theoretical calculated amount of Aliquat 336 was added to $500 \mathrm{ml}$ of toluene and stirred for almost 20 minutes. The solution prepared was passed through the hollow fiber membrane from both shell-side and tube-side for another 20 minutes. The impregnated system was allowed to dry itself for 24 hours under ambient conditions. After every experiment the module was cleaned with the distilled water until there was no trace of the ionic liquid or toluene found. For the purpose of the next experiment same procedure was followed for the impregnation of the hollow fiber supported liquid membrane module.

Experiments: After 24 hour of impregnation of HFSLM, the experiments were performed based on the pattern stated in table 2 . The experiments were performed under $25^{\circ} \mathrm{C}$ temperatures and 1 atmospheric pressure. At first, the initial sample (for the purpose of analysis) was collected from the feed solution. Next, the feed solution along with the stripping agent was putted into their respective containers.

The gear pumps were started simultaneously and the solutions were allowed to flow through the membrane module on their respective sides for 20 minutes. After 20 minutes, the second sample (for the purpose of analysis) was taken from the feed-outlet container. The two samples were preserved in cold and suitable conditions before it was sent for the mercury analysis.

\begin{tabular}{|c|c|c|c|c|c|}
\hline & $\begin{array}{l}\text { Aliquat } \\
\text { Conc. (M) }\end{array}$ & $\begin{array}{l}\text { Volumetric } \\
\text { Flow-rate } \\
\text { (ml/minutes) }\end{array}$ & $\begin{array}{l}\text { Stripping } \\
\text { Agent } \\
\text { Conc. (M) }\end{array}$ & $\begin{array}{l}\mathrm{Hg} \text { Conc. } \\
(\mathrm{ppb})\end{array}$ & $\begin{array}{l}\text { Co Conc. } \\
\text { (ppb) }\end{array}$ \\
\hline \multicolumn{6}{|c|}{ Experiment 1} \\
\hline Part-1 & 0.1 & 100 & 0.05 & 40 & 0 \\
\hline Part-2 & 0.1 & 100 & 0.05 & 40 & 20 \\
\hline Part-3 & 0.1 & 100 & 0.05 & 40 & 40 \\
\hline \multicolumn{6}{|c|}{ Experiment 2} \\
\hline Part-1 & 0.1 & 100 & 0.05 & 40 & 40 \\
\hline Part-2 & 0.15 & 100 & 0.05 & 40 & 40 \\
\hline Part-3 & 0.2 & 100 & 0.05 & 40 & 40 \\
\hline \multicolumn{6}{|c|}{ Experiment 3} \\
\hline Part-1 & 0.1 & 100 & 0.025 & 40 & 40 \\
\hline Part-2 & 0.1 & 100 & 0.05 & 40 & 40 \\
\hline Part-3 & 0.1 & 100 & 0.075 & 40 & 40 \\
\hline \multicolumn{6}{|c|}{ Experiment 4} \\
\hline Part-1 & 0.1 & 50 & 0.05 & 40 & 40 \\
\hline Part-2 & 0.1 & 100 & 0.05 & 40 & 40 \\
\hline Part-3 & 0.1 & 200 & 0.05 & 40 & 40 \\
\hline
\end{tabular}

Table 2: The number of experiments with variable parameter.

Mercury analysis: Initially, three standard solutions of different concentration were prepared $(1 \mathrm{~g} / \mathrm{L}, 1 \mathrm{mg} / \mathrm{L}$ and $5 \mathrm{mg} / \mathrm{L})$. The commercial grade solution of mercury was used for the preparation of the standards by following the manuals of HydrEA. The diluent used were $37 \% \mathrm{HCl}$ and $65 \% \mathrm{HNO}_{3}$.

The analyzer was first rinsed with $\mathrm{HCl}$ and $\mathrm{HNO} 3$ and the standards were placed in their corresponding slots. The samples were introduced to the HydrEA and the respective results were observed in both graphical and numerical format. The data collected was analyzed. The mercury removal efficiency was calculated by using the equation (1) given below:- 


$$
\text { Efficiency }=\frac{\text { Inlet conc. }- \text { Outlet conc. }}{\text { Inlet conc. }} \times 100-(1)
$$

\section{Results and Discussion}

\section{Hollow Fiber Supported Liquid Membrane}

The hollow fiber supported liquid membrane was constructed of hydrophobic micro porous membranes which acted as permeable barriers between the two of the flowing liquid phases. The driving force for the targeted component from one stage to another stage is determined by the concentration gradient between the liquid phases and it was considered as most vital feature of the membrane separation technique. The liquid phases were in parallel counter current flow which increased the local concentration gradient along with the effective surface area of contact required for mass transfer. This increase in mass transfer enhanced the separation efficiency and subsequently reduced the associated costs quite effectively. [16-20].

The feed and stripping phase reactions are represented by the chemical reaction equation (2)and (3) where they show how the intermediates to react with the ionic liquid on both sides of the membrane were formed. The mercury ions of feed phase reacted with the extractant to form a mercury complex molecule at the feedmembrane border and the chemical reaction is represented by the equation (4). The complex molecule formed diffused through the liquid membrane and reacted with stripping phase at the membranestripping boundary and the chemical reaction is represented by equation (5). Most importantly, the mechanism of extraction and stripping was achieved in a single step simultaneously.

$$
\begin{aligned}
& \mathrm{Hg}^{2+}+\mathrm{iCl}^{-} \leftrightarrow \\
& \mathrm{HgCl}_{\mathrm{i}}{ }^{2-\mathrm{i}}-(2) \\
& \mathrm{NH}_{2}-(\mathrm{C}-\mathrm{S})-\mathrm{NH}_{2}+\mathrm{HCL} \leftrightarrow \\
& \quad \mathrm{NH}_{2}-(\mathrm{C}-\mathrm{S})-\mathrm{NH}_{2}-\mathrm{HCL}-(3) \\
& \mathrm{HgCl}_{\mathrm{i}}^{2-\mathrm{i}}+(-2+\mathrm{i}) \mathrm{NR}_{4} \mathrm{Cl} \leftrightarrow \\
& \quad \mathrm{HgCl}_{\mathrm{i}-2}{ }^{2-}\left(\mathrm{NR}_{4} \mathrm{Cl}\right)_{(-2+\mathrm{i})}+(-2+\mathrm{i}) \mathrm{Cl}^{-}-(4) \\
& \mathrm{HgCl}_{\mathrm{i}}^{2-\mathrm{i}}+(-2+\mathrm{i}) \mathrm{NH}_{2}-(\mathrm{C}-\mathrm{S})-\mathrm{NH}_{2}-\mathrm{HCL} \leftrightarrow \\
& \quad \mathrm{HgCl}_{\mathrm{i}-2}\left(\mathrm{NH}_{2}-(\mathrm{C}-\mathrm{S})-\mathrm{NH}_{2}-\mathrm{HCL}\right)_{(-2+\mathrm{i})}+(-2+\mathrm{i}) \mathrm{Cl}^{-}-(5)
\end{aligned}
$$

The reactions stated in above equations are basic chemistry between molecules which made the whole process of extraction possible. The value of $\mathrm{i}$ was considered to be around 4 for the purpose of simplification and reactions were considered as the basis of the following discussion.

\section{Effect of Cobalt (II) Chloride Concentration}

The presence of the cobalt ions in the feed sample was considered to be a part of impurities in the solution. An extra effort was given to find the relationship between the concentration of cobalt and the percentage removal of mercury. The concentration range was selected to be from zero till the equivalent amount of mercury concentration (40 ppb). It was assumed, the mercury will always play the dominant character in terms of concentration in the solution. The experimental results obtained are graphically presented in Figure 2.
The graphical pattern in Figure 2 shows that there was an increase of the percentage removal value from $34 \%$ at $0 \mathrm{ppb}$ of cobalt to $57 \%$ at mercury equivalent concentration of cobalt. The presence of cobalt ions in the feed solution was found beneficial for the mercury removal. This was due to the presence of strong electrostatic interactions between electrons of the metal ions which increased ionic liquid concentration in the boundary between the feed phase and the impregnated phase. The reaction was very fast compared to the situation where there was no cobalt ion, this phenomenon is taken into consideration by AA Nayl while doing the Co (II) and $\mathrm{Ni}$ (II) separation by extraction. The perfect explanation of this particular principle is only possible when the removal efficiency of cobalt ions will also be taken into consideration and compared with the mercury. The enhancement of mercury percentage removal in presence of cobalt (II) chloride was taken as an extra advantage and $40 \mathrm{ppb}$ of cobalt concentration was used for the following experiments.

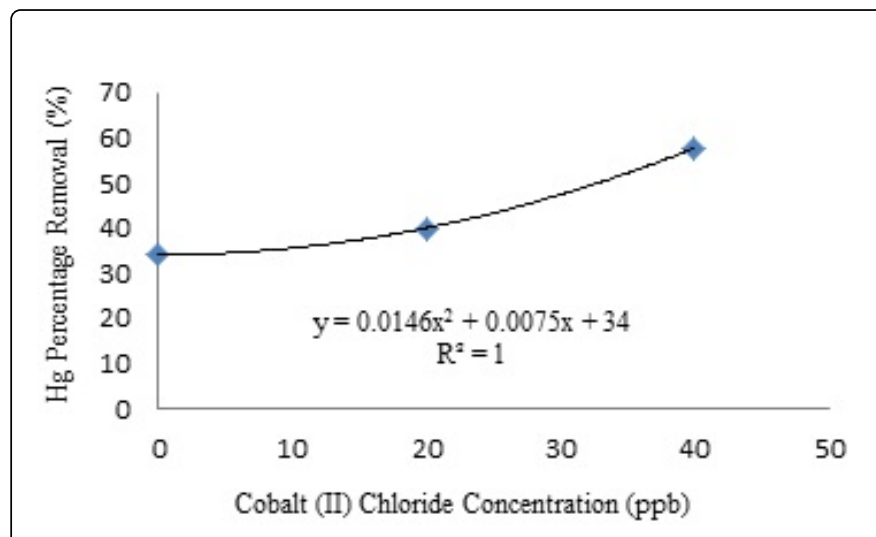

Figure 2: The graph shows the effect of cobalt (II) chloride concentration.

\section{Effect of Ionic Liquid Concentration}

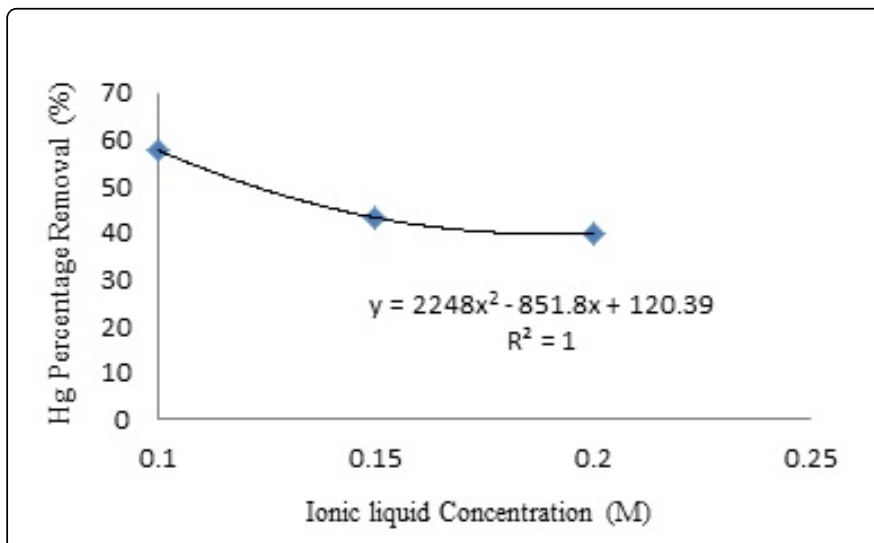

Figure 3: The graph shows the effect of ionic liquid concentration.

The ionic liquid (Aliquat 336) was used to smoothen the progress of the mercury transport to the stripping phase by carrying it through the membrane pores. According to the theory, the performance efficiency of HFSLM is proportional to ionic liquid in the pores of the membrane. Additionally, it also plays a significant role to stabilize the membrane system which is really important in commercial terms. 
Page 5 of 7

Aliquat 336 in the range of $0.1 \mathrm{M}-0.2 \mathrm{M}$ was used to verify the effect of the ionic liquid extractant concentration on the removal performance of HFSLM. All the other variable parameters were kept constant. The effect of the ionic liquid concentration is represented graphically in Figure 3. The maximum value for percentage removal was found to be around $57.69 \%$ for the considered experimental range. The mercury removal percentage decreased with the increase of the ionic liquid concentration. This phenomenon can be explained by stating that an increase in the concentration of the ionic liquid increased the number of the mercury complex formed. These newly formed complex molecules resulted in high viscosity on the phase separation boundaries of HFSLM. Consequently, there was an increase in the mass transfer resistance for the diffusion of mercury. The pattern can also be explained with the help of the physical observation during the experimental time where the liquids coming out of the membrane which was found to be more towards turbidity with respect to the high concentration of ionic liquid.

Some of the related research also observed a similar kind of trend once the optimum value is reached though there is an increase in the removal percentage before the optimum value. The graphical representation in Figure 3 shows that the starting value of the ionic liquid concentration gave the maximum removal efficiency value within the stated range but may not be the optimum one. The optimum value of ionic liquid concentration is totally dependent on the fabrication method that will be used for membrane preparation. For this particular case, the maximum value was concluded as an optimum value within the range considered.

\section{Effect of Stripping Agent Concentration}

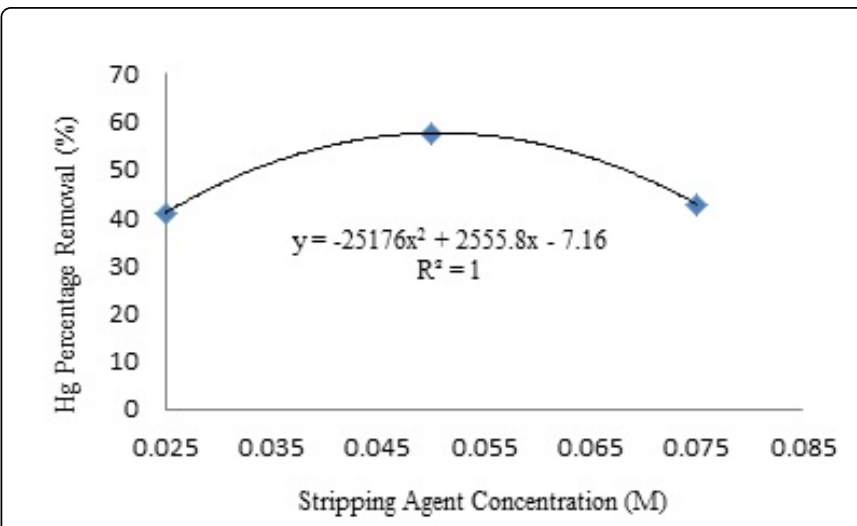

Figure 4: The graph shows the effect of stripping agent concentration.

Thiourea was selected as the stripping agent for mercury removal or extraction. For this case, the mercury which diffused through the membrane pores from the feed phase reacted with the extractant and formed unusual complex mercury molecule. The complex mercury molecule moved across to the other side of the membrane and was permeated to come in contact with the stripping phase of thiourea. Thiourea reacted with complex mercury to free the mercury ion from the membrane system and was allowed to run away with mercury ion Thiourea striping agent concentration was used within the range of $0.025 \mathrm{M}-0.75 \mathrm{M}$ to observe the effect of stripping agent concentration on the mercury removal performance of HFSLM.
The Figure 4 shows that percentage removal of mercury has increased with the increase in the value for thiourea concentration up to $0.05 \mathrm{M}$. However, the removal percentage of mercury slowly decreased with a further increase in the value of thiourea concentration. The optimum percentage removal of mercury was found to be around $58 \%$ and was achieved at $0.05 \mathrm{M}$ concentration of the stripping agent. The lowest removal efficiency was found at 0.025 $\mathrm{M}$ and $.075 \mathrm{M}$ concentrations of the thiourea within the range considered for this particular research and the value was approximately $40 \%$. The theoretical explanation for the increase in the value of the percentage removal is that as the concentration of thiourea increased it consequently enhanced the concentration gradient (which is the driving force for the diffusion through the membrane) thus improved the mass transfer of the mercury. The decline in the percentage removal value after reaching the optimum was due to the formation of the precipitation at such a high concentration gradient. The high value of concentration gradient also might have brought the cobalt ions in the reaction mechanism which might have a significant effect on the mercury removal process as well.

\section{Effect of Feed \& Stripping Agent Volumetric Flow-Rates}

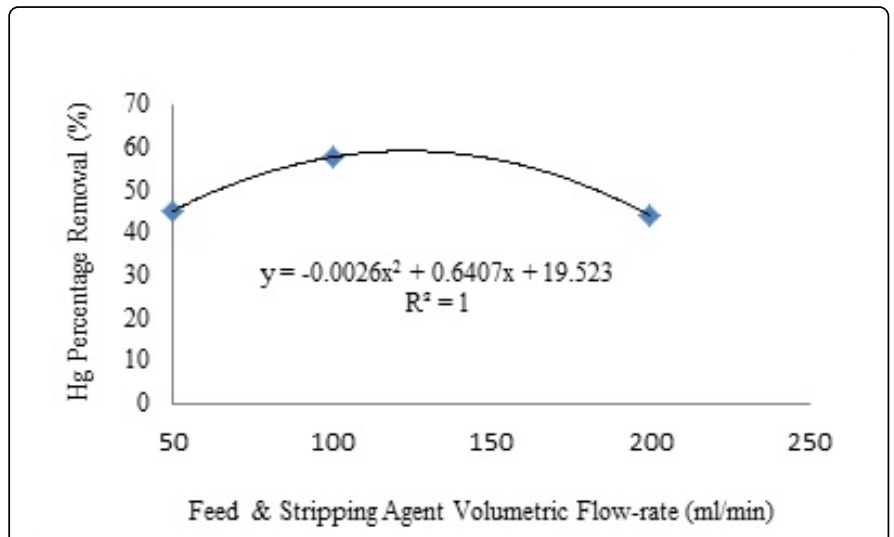

Figure 5: The graph shows the effect of feed and stripping agent volumetric flow-rates.

The purpose of this particular experiment was to investigate importance of the hydrodynamic characteristics of HFSLM. The volumetric flow rates of feed and stripping solutions were varied in the range of $50 \mathrm{ml} / \mathrm{min}$ to $200 \mathrm{ml} / \mathrm{min}$ for the 20 minutes of operational time. The results of percentage removal of the mercury extraction are shown in Figure 5. It can be seen from the figure that an increase in the volumetric flow-rates of the feed and stripping solution caused an increase in the percentage removal of mercury. This was due to increase in the number of new molecules that might have enhanced the extraction process per unit time. Another phenomenon that can explain this increase in the percentage removal of mercury is that the increase in the volumetric flow rates might have resulted in the decrease of boundary layer thickness which led to lower mass transfer resistance and thus higher flux density of the solute across the membrane and increased the metal ion transfer [21-30]

However, the percentage removal reached a peak value of around $60 \%$ at the flow-rate of $125 \mathrm{ml} / \mathrm{min}$ and started to decline. The declining phenomenon can be explained by the retention time concept. The increase in the volumetric flow-rates reduced the residence time and after a certain extent of reduction in retention time the essential 
reactions didn't have enough time to carry-out themselves as the reactants didn't have enough contact time to create a chemical interaction with each other.

\section{Conclusions}

The adverse effect of heavy metal contamination like mercury can be minimized by reducing the rate of discharge from the industrial effluents. The reduction of the mercury discharge can be achieved by using an efficient removal technique. So, it really vital to find a technique that will efficiently remove mercury from aqueous waste discharge and will possess quality, low cost, higher stability, low hazardous waste, compact size and high capacity. Hollow fiber supported ionic liquid was selected as the best possible solution and different operating parameters of this particular system were varied to find the best possible percentage removal of mercury.

The optimum or most suitable experimental values for the HFSLM variable parameters within the considered range were found to be of $0.1 \mathrm{M}$ concentration for Aliquat 336, $0.05 \mathrm{M}$ concentration for stripping agent, $125 \mathrm{ml} / \mathrm{min}$ for the feed \& stripping agent volumetric flow-rates and $40 \mathrm{ppb}$ of cobalt (II) chloride. The system operating at the optimum conditions stated above in presence of cobalt (40 ppb) gave a maximum mercury removal percentage of almost $60 \%$. Most of the experimental values represented in the graphs show patterns, which are in alignment with some of the high ranked research papers of recent years. Consequently, in conclusion it can be surmised that the outcome of this particular research is strongly capable of contributing a precise and accurate thought on the subject of the hollow fiber supported ionic liquid membrane system for the mercury removal in presence of cobalt as a contaminant.

\section{Acknowledgement}

This research is a part of University of Malaya (UM) final year project. A very special acknowledgement and appreciation to Senior Fellow Researcher (Dr.) Jayakumar Natesan Subramanian Nayagar, Professor (Dr.) Mohamed Kheireddine Bin Taieb Aroua, Senior Lecturer (Dr.) Mahar Diana Hamid and lastly Assistant Engineer (Mr.) Osman Bin Sadikin. Further supported acknowledgements are towards the academician and technical staffs of the Chemical Engineering Department (UM) and the Chemistry Department (UM) who made this research possible.

\section{References}

1. Chakrabarty K, Saha P, Ghoshal A (2010) Separation of mercury from its aqueous solution through supported liquid membrane using environmentally benign diluent. Journal of Membrane Science 350: 395-401.

2. Shaik A, Chakrabarty K, Saha P, Ghoshal A (2010) Separation of $\mathrm{Hg}(\mathrm{II})$ from Its Aqueous Solution Using Bulk Liquid Membrane. Industrial \& Engineering Chemistry Research 49: 2889-2894.

3. Ghodbane I, Hamdaoui O (2008) Removal of mercury (II) from aqueous media using eucalyptus bark: Kinetic and equilibrium studies. Journal of Hazardous Materials 160: 301-309.

4. Hassan S, Awwad N, Aboterika A (2008) Removal of mercury(II) from wastewater using camel bone charcoal. Journal of Hazardous Materials 154: 992-997.

5. Miretzky P, Cirelli A (2009) Hg(II) Removal from water by chitosan and chitosan derivatives: A review. Journal of Hazardous Materials 167: 10-23.

6. Review Correction Cycle (1979) Medical Care 17: 25.
7. Stojanovic A, Keppler B (2012) Ionic Liquids as Extracting Agents for Heavy Metals. Separation Science and Technology 47: 189-203.

8. Lothongkum A, Ramakul P, Sasomsub W, Laoharochanapan S, Pancharoen U (2009) Enhancement of uranium ion flux by consecutive extraction via hollow fiber supported liquid membrane. Journal of the Taiwan Institute of Chemical Engineers 40: 518-523.

9. Pancharoen U, Somboonpanya S, Chaturabul S, Lothongkum A (2010) Selective removal of mercury as $\mathrm{HgCl} 42$ - from natural gas well produced water by TOA via HFSLM. Journal of Alloys and Compounds 489: 72-79.

10. Weerawat P, Nattaphol V, Ura P (2003) Selective recovery of palladium from used aqua regia by hollow fiber supported with liquid membrane. Korean Journal Of Chemical Engineering 20: 1092-1096.

11. Usapein P, Lothongkum A, Ramakul P, Pancharoen U (2009) Efficient transport and selective extraction of $\mathrm{Cr}(\mathrm{VI})$ from waste pickling solution of the stainless steel-cold rolled plate process using Aliquat 336 via HFSLM. Korean Journal of Chemical Engineering 26: 791-798.

12. Seddon K (2003) Ionic liquids: A taste of the future. Nature Materials 2: 363-365.

13. Wasserscheid P, Keim W (2000) Ionic Liquids-New "Solutions" for Transition Metal Catalysis. Angewandte Chemie 39: 3772-3789.

14. Welton $\mathrm{T}$ (2010) ChemInform Abstract: Room-Temperature Ionic Liquids. Solvents for Synthesis and Catalysis. Cheminform 30.

15. Goharshadi E, Moosavi M (2008) Thermodynamic properties of some ionic liquids using a simple equation of state. Journal of Molecular Liquids 142: 41-44.

16. Nayl A (2010) Extraction and separation of Co (II) and Ni (II) from acidic sulfate solutions using Aliquat 336. Journal of Hazardous Materials 173(2010): 223-230.

17. Juang R, Wang Y (2003) Use of complexing agents for effective ionexchange separation of $\mathrm{Co}(\mathrm{II}) / \mathrm{Ni}(\mathrm{II})$ from aqueous solutions. Water Research 37: 845-852.

18. Kao H, Juang R (2003) Hindered Membrane Diffusion in the Nondispersive Stripping of Co(II) from Organic Amine Solutions with Hydrochloric Acid. Industrial \& Engineering Chemistry Research 42: 6181-6187.

19. Juang R, Kao H (2005) Extraction separation of Co (II)/Ni (II) from concentrated $\mathrm{HCl}$ solutions in rotating disc and hollow-fiber membrane contactors. Separation and Purification Technology 42: 65-73.

20. Gega J (2001) Separation of $\mathrm{Co}(\mathrm{II})$ and $\mathrm{Ni}(\mathrm{II})$ ions by supported and hybrid liquidmembranes. Separation and Purification Technology 23: 551-558.

21. Kemperman I, Russ M, Clark W (1996) Pain perception in self-injurious borderline patients. Biological Psychiatry 39: 537-538.

22. Lozano I, Calvo D, Rondan J (2011) Letter by Lozano et al Regarding Articles "Transcatheter Valve-in-Valve Implantation for Failed Bioprosthetic Heart Valves" and "Percutaneous Therapy for Valvular Heart Disease: A Huge Advance and a Huge Challenge to Do It Right". Circulation 123: 15.

23. Zidi C, Tayeb R, Ali M, Dhahbi M (2010) Liquid-liquid extraction and transport across supported liquid membrane of phenol using tributyl phosphate. Journal of Membrane Science 360: 334-340.

24. Chakrabarty K, Saha P, Ghoshal A (2010) Simultaneous separation of mercury and lignosulfonate from aqueous solution using supported liquid membrane. Journal of Membrane Science 346: 37-44.

25. Fábrega F, Mansur M (2007) Liquid-liquid extraction of mercury (II) from hydrochloric acid solutions by Aliquat 336. Hydrometallurgy 87 : 83-90.

26. Lothongkum A, Suren S, Chaturabul S, Thamphiphit N, Pancharoen U (2011). Simultaneous removal of arsenic and mercury from natural-gasco-produced water from the Gulf of Thailand using synergistic extractant via HFSLM. Journal of Membrane Science 369: 350-358.

27. Gabelman A, Hwang S (1999) Hollow fiber membrane contactors. Journal of Membrane Science 159: 61-106.

28. Shen S, Smith K, Cook S, Kentish S, Perera J, et al. (2009) Phenol recovery with tributyl phosphate in a hollow fiber membrane contactor: 
Citation: Neon MHK and Nayagar JNS (2017) Mercury Extraction in Presence of Cobalt Using Hollow Fiber Supported lonic Liquid Membrane. J Membr Sci Technol 7: 170. doi:10.4172/2155-9589.1000170

Page 7 of 7

Experimental and model analysis. Separation and Purification Technology: 69: 48-56.

29. Plambeck E, Hope C (1996) Energy Policy 24: 783-793.
30. Mansourizadeh A, Ismail A (2009) Hollow fiber gas-liquid membranecontactors for acid gas capture: A review. Journal of Hazardous Materials 171:38-53. 